\title{
The application of numerical debris flow modelling for the generation of physical vulnerability curves
}

\author{
B. Quan Luna ${ }^{1}$, J. Blahut ${ }^{2}$, C. J. van Westen ${ }^{1}$, S. Sterlacchini ${ }^{3}$, T. W. J. van Asch ${ }^{4}$, and S. O. Akbas \\ ${ }^{1}$ Faculty of Geoinformation Science and Earth Observation (ITC), University of Twente, P.O. Box 6, \\ 7500 AA Enschede, The Netherlands \\ ${ }^{2}$ Institute of Rock Structure and Mechanics, Academy of Sciences of the Czech Republic, V Holešovičkách 41, \\ 18209 Prague, Czech Republic \\ ${ }^{3}$ Institute for the Dynamic Environmental Processes, National Research Council (CNR-IDPA), Piazza della Scienza 1, \\ 20126 Milan, Italy \\ ${ }^{4}$ Faculty of Geosciences, Utrecht University, Utrecht, The Netherlands \\ ${ }^{5}$ Civil Engineering Department, Gazi University, Ankara, Turkey
}

Received: 24 September 2010 - Revised: 7 March 2011 - Accepted: 2 April 2011 - Published: 25 July 2011

\begin{abstract}
For a quantitative assessment of debris flow risk, it is essential to consider not only the hazardous process itself but also to perform an analysis of its consequences. This should include the estimation of the expected monetary losses as the product of the hazard with a given magnitude and the vulnerability of the elements exposed. A quantifiable integrated approach of both hazard and vulnerability is becoming a required practice in risk reduction management. This study aims at developing physical vulnerability curves for debris flows through the use of a dynamic run-out model. Dynamic run-out models for debris flows are able to calculate physical outputs (extension, depths, velocities, impact pressures) and to determine the zones where the elements at risk could suffer an impact. These results can then be applied to consequence analyses and risk calculations. On 13 July 2008, after more than two days of intense rainfall, several debris and mud flows were released in the central part of the Valtellina Valley (Lombardy Region, Northern Italy). One of the largest debris flows events occurred in a village called Selvetta. The debris flow event was reconstructed after extensive field work and interviews with local inhabitants and civil protection teams. The Selvetta event was modelled with the FLO-2D program, an Eulerian formulation with a finite differences numerical scheme that requires the specification of an input hydrograph. The internal stresses are isotropic and the basal shear stresses are calculated using a quadratic model. The behaviour and run-out of the flow was reconstructed. The significance of calculated values of the flow depth, velocity, and pressure were investigated in terms
\end{abstract}

Correspondence to: B. Quan Luna (quanluna@itc.nl) of the resulting damage to the affected buildings. The physical damage was quantified for each affected structure within the context of physical vulnerability, which was calculated as the ratio between the monetary loss and the reconstruction value. Three different empirical vulnerability curves were obtained, which are functions of debris flow depth, impact pressure, and kinematic viscosity, respectively. A quantitative approach to estimate the vulnerability of an exposed element to a debris flow which can be independent of the temporal occurrence of the hazard event is presented.

\section{Introduction}

The increase in population and resulting demand for resources has given rise to a continuous pressure to settle in places were the interaction between humans and continuous land processes becomes a potential risk (Nadim and Kjekstad, 2009). For this reason, it is essential to analyze the possible damage that the hazard process can yield in the af fected sectors. A quantifiable integrated approach of both hazard and risk is becoming a required practice in risk reduction management (Fell and Hartford, 1997; Duzgun and Lacasse, 2005). This quantitative assessment should include the expected losses as the product of the hazard with a given magnitude, the costs of the elements at risk, and their vulnerability (Uzielli et al., 2008). In the past, several authors have proposed different methods to quantify the risk by estimating the hazard in a heuristic-empirical or statistical manner; while assessing the vulnerability of the affected elements in a qualitative method (Liu and Lei, 2003; Remondo et al., 2008; Zêzere et al., 2008).

Published by Copernicus Publications on behalf of the European Geosciences Union. 
In order to improve the results of a debris flow risk assessment, it is necessary to analyze the hazard event using quantitative information in every step of the process (van Asch et al., 2007) and the vulnerability of the elements exposed. The contribution of the dynamic run-out models inside a quantitative assessment is to reproduce the distribution of the material along the course, its intensity, and the zone where the elements will experience an impact. For this reason, dynamic run-out models have been used in recent years as a tool that links the outputs of a debris flow hazard initiation/susceptibility modelling (released volumes) with physical vulnerability curves.

\subsection{Numerical modelling for hazard analysis in a Quantitative Risk Assessment (QRA)}

Different approaches and methods have been developed in the past for a quantitative risk analysis using dynamic runout models and where the vulnerability of the elements at risk is described in a quantitative or qualitative manner. In this direction, Bell and Glade (2004) performed a quantitative risk analysis (focusing on the risks to life) in NWIceland for debris flows and rock falls. Their approach to the hazards is based on empirical and process modelling that resulted in specific run-out maps. The hazard zones were determined based on the recurrence interval of the respective processes. For the determination of the respective levels of vulnerability, a semi-quantitative approach defined by matrices was used based on available literature and the authors' past findings (Glade, 2004). Their calculated vulnerability levels were incorporated into a consequence analysis that included the definition of elements at risk, the determination of spatial and temporal probabilities of impact, and the seasonal occurrence of the event. Calvo and Savi (2008) proposed a method for a risk analysis in a debris flow-prone area in Ardenno (Italian Alps), utilizing a Monte Carlo procedure to obtain synthetic samples of debris flows. To simulate the propagation of the debris flow on the alluvial fan, the FLO2D model (O'Brien et al., 1993) was applied and probability density functions of the outputs of a model (forces) were obtained. Three different vulnerability functions were adopted to examine their effect on risk maps. Muir et al. (2008) presented a case study of quantitative risk assessment to a sitespecific natural terrain in Hong Kong, where various scenarios were generated with different source volumes and sets of rheological parameters derived from the back analyses of natural terrain landslides in Hong Kong. Debris mobility modelling was performed using the Debris Mobility Model (DMM) software developed by the Geotechnical Engineering Office (Kwan and Sun, 2006), which is an extension of Hungr's (1995) DAN model. They derived probability distributions from past events run-outs and calculated the probability distribution of debris mobility for each volume class. Regarding the vulnerability, they used an "Overall Vulnera- bility Factor" (OVF) and the average number of vulnerable population in a given facility directly hit by a landslide. The OVF was derived from the landslide volume, location of the elements at risk, and the protection a facility can offer. Individual risk was calculated as the summation of the product of the frequency of a flow affecting the facility and the vulnerability of the most vulnerable individual for each of the scenarios. They also calculated the societal risk. Castellanos (2008) performed a local risk assessment based on the back-analysis of one historical landslide in Cuba. Based on the parameters obtained from the modelling of past events, run-out simulations were carried out with a beta version of the MassMov2D software (Beguería et al., 2009) for twelve potential zones. Vulnerability curves based on the depth of the flow and the conditions of the buildings were generated using detailed building typology characteristics and run-out results, and economic risk values were computed for three scenarios. Zimmerman (2005) described Switzerland's new approach of natural hazards and risk management using the Sörenberg debris flow as an example. For the Sörenberg event, hazard maps were prepared according to three probability classes scenarios. The scenarios were based on past events and field verification. Debris-flow run-out was simulated using a random walk approach (Gamma, 2000) by applying a simple model that assumes that the motion is mainly governed by two frictional components: a sliding friction coefficient and a turbulent friction coefficient that is determined by a Chezy-type relation (Rickenmann, 1990). Results of the modelling were displayed as intensity maps. Federal recommendations provide definite criteria for the intensity classes based on the height and the velocity of the flow. Adjustment of the land-use plans and building codes were established regarding the intensity classes. Jakob and Weatherly (2005) quantified debris flow hazard and risk on the Jonas Creek fan in Washington, USA. They constructed frequency-magnitude graphs to build different return period scenarios as an input to a debris flow run-out model. The FLO-2D model was used to calculate maximum flow depths and velocities in order to assess the hazard. Intensity maps were developed based on the modeled outputs of each modeled scenario. Potential deaths were calculated assuming that in the high intensity areas the vulnerability is equal to 1 , while the vulnerability is equal to 0 in the medium and low intensity zones. In terms of risk management, Crosta et al. (2005) carried out a costbenefit analysis for the village of Bindo in the Valsassina valley (Central Pre-alps, Italy) where a part of an active slope is still a threat. They identified different mitigation plans such as a defensive structure, monitoring, and a combination of both. They built hazard scenarios with a method that coupled a stability analysis with a run-out assessment for different potential landslides. The stability analysis was modeled using a 2-D numerical code and the run-out was simulated with the quasi-three-dimensional finite element method of Chen and Lee (2000) in the Lagrangian frame of reference. The different scenarios were compared with a scenario where no 
mitigation action was introduced. A cost-benefit analysis of each scenario was performed considering the direct effect on human life, houses, and lifelines.

The recent work done by means of numerical physical modelling within a risk analysis suggests that dynamic runout models (correctly used) can be of practical assistance when attempting to quantify the assessment. Together with a good understanding of the slope processes and their relationship with other conditional factors, run-out models results can be used in a hazard analysis to: estimate the spatial probability of the flow affecting a certain place with detailed outputs as deposition patterns, travelled distance and path, and velocities and impact pressures. Results obtained from the run-out modelling are directly involved as factors that influence and affect the vulnerability of an exposed element. However, quantitative vulnerability information for landslides is difficult to obtain due to the large variability in landslides types, the difficulty in quantifying landslides magnitude, and the lack of substantial historical damage databases (van Westen et al., 2006; Douglas, 2007).

\subsection{Physical vulnerability assessment}

Several efforts have been made in the past to define and assess the vulnerability of an element or group of elements exposed to a landslide hazard. The vulnerability can be classified as: physical, functional, and systemic vulnerability. The physical vulnerability relates to the consequences or the results of an impact of a landslide on an element (Glade, 2003). Functional vulnerability depends on the damage level of the element at risk and its ability to keep functioning after an event (Leone et al., 1996). Systemic vulnerability defines the level of damage between the interconnections and functionality of the elements exposed to a hazard (Pascale et al., 2010). In this paper, a focus on the physical vulnerability will be highlighted with regard to a method which is commonly used in a quantitative risk assessment.

In a quantitative risk assessment, physical vulnerability is commonly expressed as the degree of loss or damage to a given element within the area affected by the hazard. It is a conditional probability, given that a landslide with a certain magnitude occurs and the element at risk is on or in the path of the landslide. Physical vulnerability is a representation of the expected level of damage and is quantified on a scale of 0 (no loss or damage) to 1 (total loss or damage) (Fell et al., 2005). Thus, vulnerability assessment requires an understanding of the interaction between the hazard event and the exposed element. This interaction can be expressed by damage or vulnerability curves.

Some progress has been made in developing vulnerability curves, matrices, and functions for several types of hazards and mass movements. Extensive work has been carried out by FEMA (Federal Emergency Management Agency) on vulnerability functions for earthquakes, floods, and hurricanes. These functions are used in the HAZUS (Hazard
US) software application to quantitatively estimate the losses in terms of direct costs (e.g. repair, loss of functionality), as well as regional economic impact and casualties (Hazus, 2006). In the case of snow avalanches, Wilhelm (1998) obtained a function by analysing the damages caused in terms of impact pressure by dense snow avalanches on concrete buildings with reinforcement. The building vulnerability was defined as the ratio of the cost of repairing the damages and the value of the building. Based on the function proposed by Wilhelm (1998), Cappiabanca et al. (2006) developed a function for people inside the buildings. Using the same approach of relating the expected losses of a structure with the impact pressures of the avalanche, Barbolini et al. (2004) proposed vulnerability functions for buildings and persons for powder snow events. To overcome the scarcity of well documented events and their consequences, Bertrand et al. (2010) used numerical models to simulate the structure behaviour under snow avalanche loading. The structures were modelled in three dimensions with a finite element method (FEM), and a damage index was defined on global and local parameters of the buildings (e.g. geometry of the structure, compressive strength of the concrete). The vulnerability was established as a function of the impact pressure and the structure features. For rock falls, Heinimann (1999) estimated vulnerability curves as damage functions of six different categories (type) of buildings related to the intensity of the rock fall. The response of reinforced concrete buildings to rock fall impact was investigated by Mavrouli and Corominas (2010), considering a single hit on the basement columns. They calculated for a range of rock fall paths and intensities, a damage index (DI) defined as the ratio of structural elements that fail to the total number of structural elements.

Regarding vulnerability functions for landslide and debris flow hazards, Kaynia et al. (2008) applied to a real event the proposed probabilistic methodology of Uzielli et al. (2008) to estimate the physical vulnerability of building structures and the population to landslides. Vulnerability is defined quantitatively as the product of landslide intensity and the susceptibility of elements at risk. The uncertainties are considered by a First-Order Second Moment approach (FOSM). This work was complemented by Li et al. (2010) by proposing new functions for the vulnerability of structures and persons based on the landslide intensity and the resistance of the exposed elements. Using another type of procedure to assess the vulnerability, Galli and Guzzetti (2007) gathered information of past events in Umbria (Italy) that have damaged buildings and roads. They established functions between the area of the landslide and the vulnerability of buildings, major roads, and minor roads. To assess the vulnerability to a debris flow, Haugen and Kaynia (2008) proposed that the impact of a flow sets a structure in a vibratory motion. Structural vulnerability is defined by a damage state probability. This was approached using the principles of dynamic response of simple structures to earthquake excitation and fragility curves proposed in HAZUS. Fuchs et al. (2007) used 
a well-documented debris flow event in the Austrian Alps to derive a vulnerability function for brick masonry and concrete buildings. They defined a damage ratio that describes the amount of damage related to the overall damage potential of the structure. A vulnerability function was created from the calculated damage ratio and the debris flow intensity (flow height). A comprehensive review of several qualitative vulnerability methods used in landslide risk analysis was made by Glade (2003).

Whereas the above mentioned examples analyze the hazard separately from the vulnerability of the elements at risk, our aim is to use the strength of the debris flow run-out models to quantify physical vulnerability by means of the impact pressure outputs. We present an integrated approach of detailed rainfall data and dynamic modelling to calculate the intensity and run-out zone of the 2008 Selvetta debris flow that caused damage to thirteen buildings. The debris flow event was reconstructed and back-analyzed. Geomorphologic investigations were carried out to study the behaviour of the flow and intensity aspects such as run-out distances, velocities, and depths. Synthetic physical vulnerability curves were prepared based on the flow depth, impact pressures, and kinematic viscosity. These curves relate the physical outputs of the modelling and the economic values of the elements at risk.

\section{Selvetta study site and past events in the region}

The Selvetta study site is situated inside the Valtellina Valley in the Italian Central Alps (Fig. 1) and administratively is a part of the Colorina municipality. Geomorphologically, it belongs to the Orobic Alps which are forming the north-facing slopes of the Valtellina Valley (a U-shaped valley profile derived from Quaternary glacial activity). Selvetta is located in a north-facing slope of the valley. The slopes are mainly composed of metamorphic rocks (gneiss, mica schist, phyllite, and quartzite) and intrusive rock units, with subordinate sedimentary rocks (Crosta et al., 2003). On less steep parts, two Pleistocene glacial terraces could be distinguished at the height of about $560-760 \mathrm{~m}$ a.s.l. and $1120-1240 \mathrm{~m}$ a.s.l. The lower sections are covered with glacial, fluvio-glacial, and colluvial deposits of variable thickness.

Valtellina Valley is an active region with respect to geomorphologic processes and mass movements. In the recent past, the valley has suffered from major catastrophic events in terms of flooding and landslides. In May 1983, heavy precipitations triggered more than 200 shallow landslides and debris flows in Valtellina. A cumulated precipitation of $453 \mathrm{~mm}$ was measured during the month, which corresponds to $34 \%$ of the total annual precipitation. Landslides happened mainly on vine-terraced slopes and most of the landslides started on slopes between $30^{\circ}$ and $40^{\circ}$. Three soilslips evolved into larger debris flows with lengths from 300 to $460 \mathrm{~m}$ and areas reaching $60000 \mathrm{~m}^{2}$, causing 14 casualties

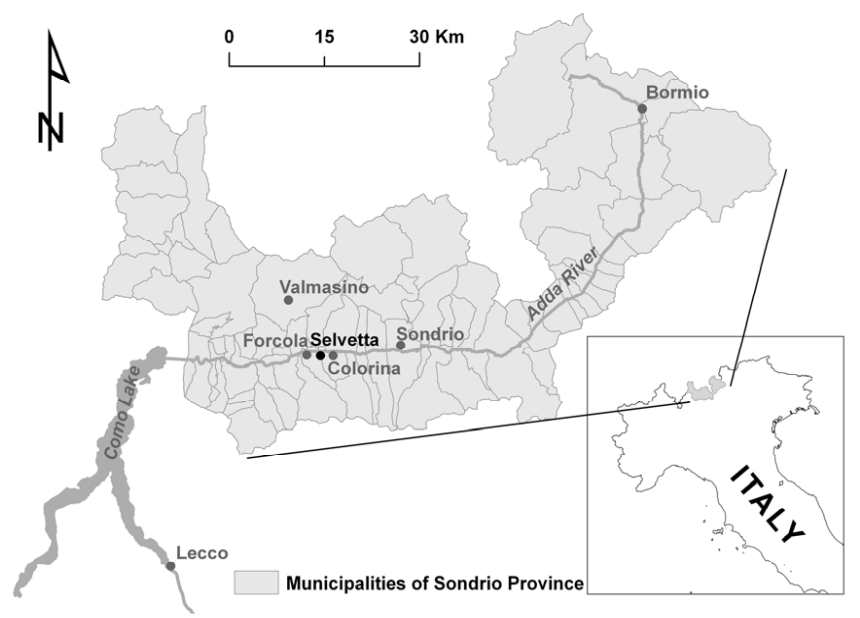

Fig. 1. Location of the Selvetta case study area.

(Cancelli and Nova, 1985). In July 1987, more than 500 mass movements were triggered by a severe rain storm (Crosta et al., 1990). Five villages and the transportation infrastructure were critically damaged. A total of 25000 evacuated persons, 53 casualties and 2000 million euros $(€)$ of damages were recorded (Luino, 2005). From 14 to 17 November 2000, prolonged and intense rainfalls triggered about 260 shallow landslides in Valtellina (Crosta et al., 2003). About 200 soil slips and slumps took place in the terraced slopes, and one third of them evolved into debris flows (Chen et al., 2006). In November 2002, the Valtellina area was affected by an extreme rainfall (more than $700 \mathrm{~mm}$ ) that triggered more than 70 soil slips and debris flows. The event caused 2 casualties and extensive damages to structures and economic activities, evaluated in 500 millions of euros (Aleotti et al., 2004).

\section{The Selvetta 2008 debris flow}

The Selvetta debris flow event took place on Sunday, 13 July 2008. During this day, the majority of the Valtellina Valley was isolated from the rest of Lombardy Region because of intense precipitations that caused blockage of the state road S.S.38 connecting the capital of the province Sondrio with the lower part of the valley. Torrents caused temporal inundation of the main valley floor with about $0.5 \mathrm{~m}$ of water on the main road and railway line. The only accesses to the upper part of the valley were via Aprica Pass and from Switzerland. The response team of the Civil Protection and another fast response teams were evacuating people from the affected area. Total number of evacuees in the Valtellina valley was around 220 people and reached around 300 in Lombardy Region. The most severely affected municipalities were Valmasino, Forcola, and Colorina where several debris flows and mud flows occurred. 
The largest muddy-debris flow occurred in the village of Selvetta. According to the morphological classification of debris flows for the South-Central Alps proposed by Crosta et al. (1990), this debris flow can be classified as a debris avalanche evolving into channelled debris flow. The debris flow event was reconstructed after extensive field work and interviews with local inhabitants and civil protection teams. At first, several rock blocks of a size up to $2 \mathrm{~m}^{3}$ fell down from the direction of a small torrent above the village. The blocks were followed by a first surge of debris and mud that damaged the houses. This surge caused the most damage in the deposition area. This was followed by a second hyperconcentrated flow with fine mud content that partially washed away the accumulation from the first wave.

The main objective of the fieldwork was to collect information to describe the behaviour of the flow during its course. Measurements of the flow depths along the path and sedimentation features that hinted the evolution of the flow were carried out. Entrainment and deposition features were mapped. The deposits inside and outside of the channel were considered and channel profiles were made in locations where the velocities and discharge of the flow could be deduced.

The evolution of the flow in terms of velocity was reconstructed by the use of empirical formulas. The estimation of the velocity is important to evaluate the flow behaviour and assess its rheology. To derive the mean flow velocity in each channel cross-section, the superelevation formula (Eq. 1) proposed by McClung (2001) and Prochaska et al. (2008) was applied:

$v=\sqrt{\frac{R_{\mathrm{c}} g}{k} \frac{\Delta h}{b}}$

where, $v$ is the mean velocity of the flow $\left(\mathrm{m} \mathrm{s}^{-1}\right), R_{\mathrm{c}}$ is the channel's radius curvature $(\mathrm{m}), g$ is the gravity acceleration $\left(\mathrm{m} \mathrm{s}^{-2}\right), \Delta h$ is the superelevation height $(\mathrm{m}), k$ is a correction factor for the viscosity, and $b$ is the flow width (m). Hungr (2007) in Prochaska et al. (2008) indicated that the value of the correction factor can be usually " 1 ", with the exception of cases with sharp bends where some shock waves develop.

Geomorphologic investigations allowed distinguishing the following five main sections of the flow: (1) the proper scarp, (2) path in forested area, (3) path on alpine meadows, (4) accelerating section, and (5) accumulation area (Fig. 2).

The initiation area of the flow was situated approximately at $1760 \mathrm{~m}$ a.s.l. in a coniferous forest. The proper scarp was very small, with an area of about $20 \mathrm{~m}^{2}$ and a height about $0.5 \mathrm{~m}$. The debris flow originated as a soil-slip in thin colluvial cover on a very steep $\left(>45^{\circ}\right)$ forested slope. This suggests that the flow started as a small failure and gained momentum with additional entrained material from the channel bed and walls. Another important source for the increase

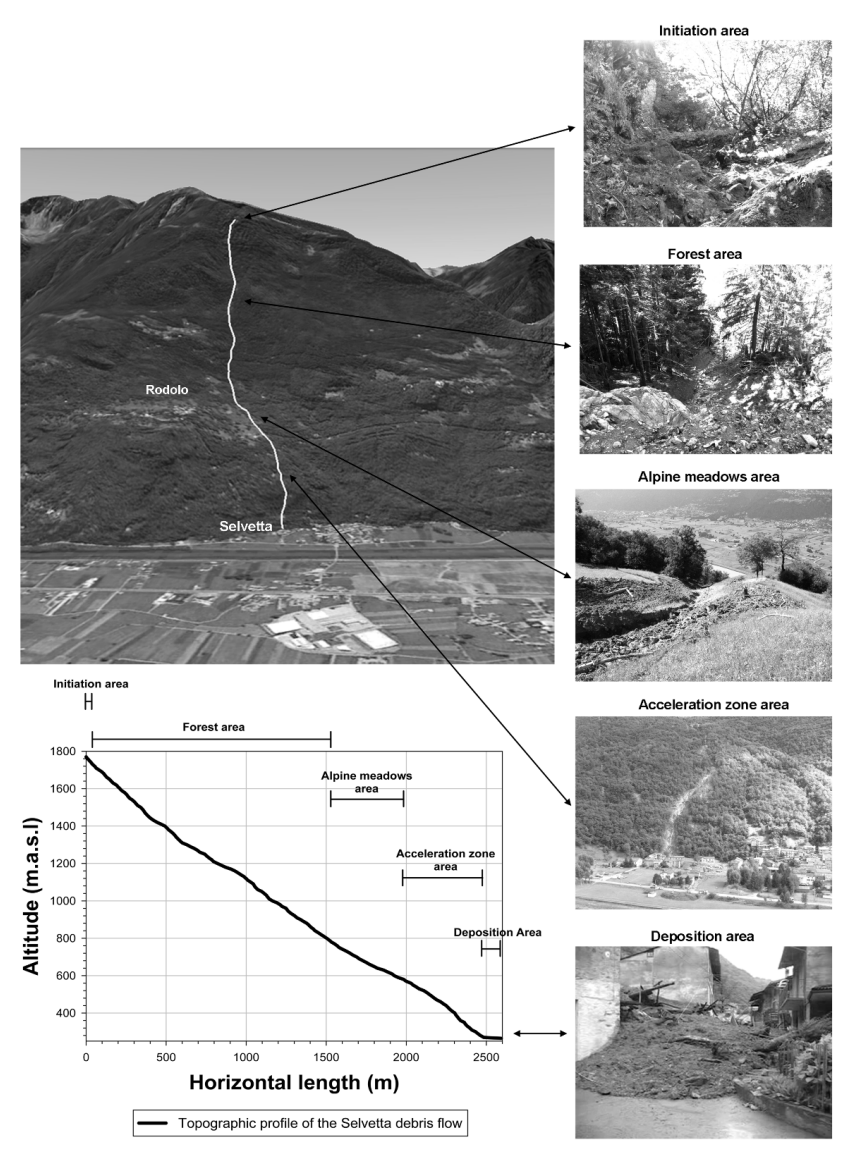

Fig. 2. Google image and profile of the Selvetta debris flow path with the five main morphological sections determined on the field.

of volume and the mobility of the flow was the inclusion to the flow of the rainfall run-off and the reactivation of water springs formed by the increase of the ground water table. After some tens of meters the flow became larger and started to erode the channel to the bedrock. The channel erosion was associated with the acceleration of the flow on steeper parts of the slope and on rock steps. The average inclination of the path in the forested area is $35^{\circ}$ but there are several steps steeper than $60^{\circ}$. At $760 \mathrm{~m}$ a.s.l. the flow decreased its velocity when it reached another less steep part of alpine meadows on morainic sediments near Rodolo village (Fig. 2). The flow channel in this section of the flow was not eroded to the bedrock and the flow itself accumulated a lot of material from the upper section. On a flat glacial terrace, at the height of $640 \mathrm{~m}$ a.s.l., the flow diverged to the right side where it joined a small ravine and entered an acceleration zone area. In this section, the flow reached the highest velocity and heights. The apex of the accumulation zone starts at $310 \mathrm{~m}$ a.s.l. The accumulation zone has an area of about $9500 \mathrm{~m}^{2}$ and the volume of the deposited debris was estimated by field mapping to be around $15000 \mathrm{~m}^{3}$ (Fig. 3). The behaviour of the debris flow in the deposition area was reconstructed based on the recognition of characteristic patterns such as sediment 


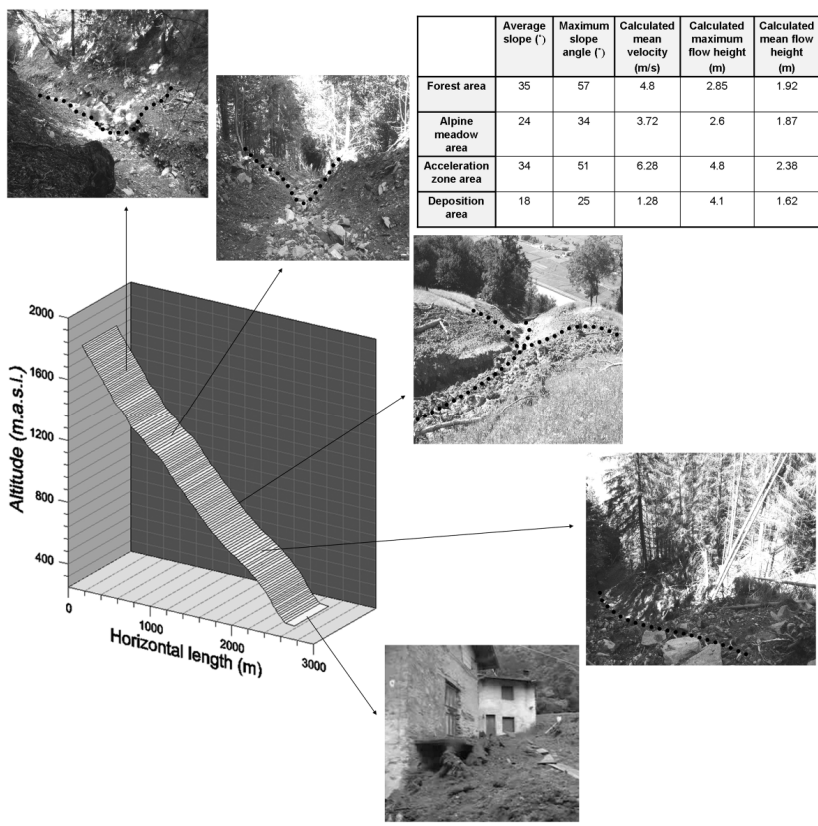

Fig. 3. Selvetta debris flow path including the calculated mean velocity, maximum flow height, and mean flow height for each morphologic section.

sorting and the angle of rest in the borders of the final deposit. Deposits consisted of a fine-grained fluid mixture with suspended coarse debris on the top and fine material on the bottom.

Precipitation records showed that the flow did not occur immediately after the peak precipitation which was recorded at 7 a.m., but with more than three hour delay. Unfortunately, there is no rain gauge in the proximity of the initiation zone. The closest one is in Morbegno (about $8 \mathrm{~km}$ from the scarp) and shows hourly peak rainfall of $22 \mathrm{~mm} \mathrm{~h}^{-1}$ between 6 and 7 a.m. (Fig. 4). The cumulated rainfall during $48 \mathrm{~h}$ before the event reached $92 \mathrm{~mm}$. Although this record did not precisely describe the situation in the initiation area, it could be used for a rough estimation of precipitation and for measuring the delay of initiation after peak precipitation, because records from other gauges in the vicinity also show the rainfall peak between 6 and 7 a.m.

One of the main characteristics of the event is the influence of the entrainment process on the flow. The channel experienced considerable deepening and bank erosion. In several parts of the channel, it was found that obstruction by large boulders and trees may have temporarily influenced the flow behaviour by causing a dam-break effect that resulted in the two different surges in the deposition area.

There are 95 buildings situated in Selvetta. The debris flow event destroyed two of them and caused damage of varying levels of severity to another eleven buildings. Structural damage was reported to the facilities located on the alluvial fan (roads). Also, a lot of damage was reported for cars and agri-
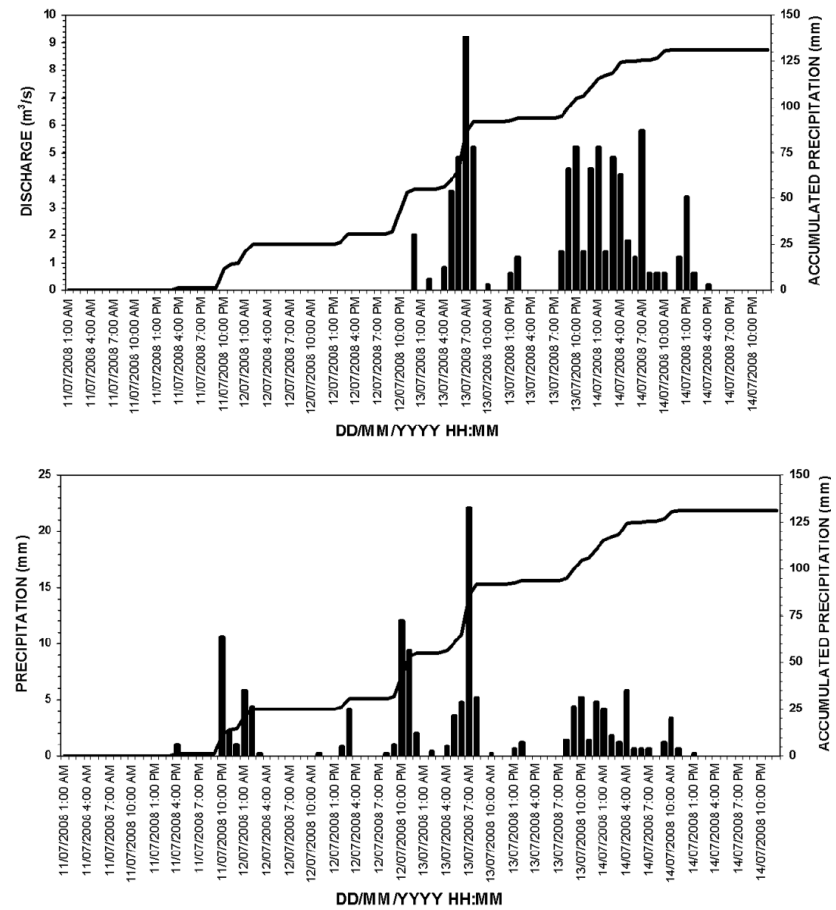

Fig. 4. Derived hydrograph of the debris flow, including the released volume and peak discharge (above) obtained from the hourly precipitation records from the Morbegno rain gauge (bottom).

cultural machinery. Fortunately, no victims or injuries were reported, mainly because of the awareness of the civil defence organization who evacuated the local inhabitants from their houses.

\section{Modelling of the event for determining vulnerability curves}

The field observations of the debris-flow event in Selvetta were taken into account and used for a back analysis using a modelling approach. They were the basis to calibrate the models and simulate the debris flow process during its course. The modelling of the Selvetta debris flow was divided into two parts. The first part was a simulation of the rainfall in the area to calculate a discharge hydrograph and the effect of the rainfall intensity in the flow. The second part was a simulation of the debris flow that included the results of modelling of the rainfall and the entrained material. The DEM available and used for the Selvetta area was a $2 \mathrm{~m}$ grid model obtained from a LIDAR survey. The FLO2D software was used to simulate the rainfall and the debris flow event (FLO-2D, 2009). A damage analysis of the elements at risk in the Selvetta event led to a vulnerability assessment which was then later combined with the modelling outputs. This resulted in three proposed vulnerability functions: flow height, impact pressure, and kinematic viscosity curves (Fig. 5). 


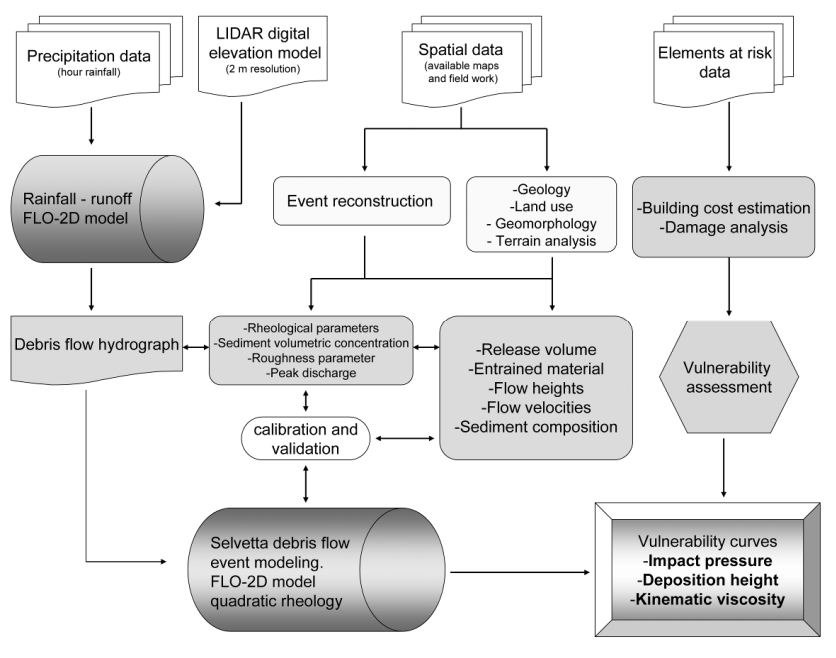

Fig. 5. Flowchart of the methodology applied in the Selvetta case study area.

The mathematical model used to model the Selvetta debris flow event was FLO-2D, which is an Eulerian twodimensional finite difference model that is able to route non-Newtonian flows in a complex topography based on a volume-conservation model. The model input is in the form of a flow hydrograph at the head of a depositional debris fan, distributing the debris over the fan surface, allowing for obstructions and pathways such as infrastructures (buildings, roads, channels, and bridges). These make the model relevant for the determination of flow patterns on the surface of a fan. The flow volume is routed through a series of tiles that simulates overland flow (2-D flow), or through line segments for channel routing (1-D flow). Flow in two dimensions is accomplished through a numerical integration of the equations of motion and the conservation of fluid volume. The governing equations are originally presented by O'Brien et al. (1993).

The FLO-2D software models the shear stress as a summation of five shear stress components: the cohesive yield stress, the Mohr-Coulomb shear, the viscous shear stress, the turbulent shear stress, and the dispersive shear stress. All these components can be written in terms of shear rates giving a quadratic rheological model function of sediment concentration. The depth-integrated rheology is expressed (after dividing the shear stresses by the hydrostatic pressure at the bottom of the flow $\gamma_{\mathrm{m}} h$ ) as Eq. (2):

$S_{\mathrm{f}}=\frac{\tau_{\mathrm{y}}}{\gamma_{\mathrm{m}} h}+\frac{K \eta V}{8 \gamma_{\mathrm{m}} h^{2}}+\frac{n_{\mathrm{td}}^{2} V^{2}}{h^{4 / 3}}$

where, $S_{\mathrm{f}}$ is the friction slope (equal to the shear stress divided by $\left.\gamma_{\mathrm{m}} h\right) ; V$ is the depth-averaged velocity; $\tau_{y}$ and $\eta$ are the yield stress and viscosity of the fluid, respectively, which are both a function of the sediment concentration by volume; $\gamma_{\mathrm{m}}$ is the specific weight of the fluid matrix; $K$ is a dimensionless resistance parameter that equals 24 for laminar flow in smooth, wide, rectangular channels, but increases with roughness and irregular cross section geometry; and $\mathrm{n}_{\mathrm{td}}$ is an empirically modified Manning $n$ value that takes into account the turbulent and dispersive (inertial grain shear) components of flow resistance. The parameters $\tau_{y}$ and $\eta$ are defined as exponential functions of sediment concentration which may vary over time. The yield stress (Eq. 3) and the viscosity (Eq. 4) are calculated as follows:

$\tau_{\mathrm{y}}=\alpha_{1} \mathrm{e}^{\beta_{1} C_{v}}$

$\eta=\alpha_{2} \mathrm{e}^{\beta_{2} C_{v}}$

where, $\alpha_{1}, \beta_{1}, \alpha_{2}$, and $\beta_{2}$ are regression constants obtained from the correlation of results of laboratory experiments, $C_{v}$ is the fine sediment concentration (silt- and clay-size particles) by volume (FLO-2D, 2009)

The boundary conditions are specified as follows: the inflow condition is defined in one or more upstream grid elements with a hydrograph (water discharge vs. time) and values of $C_{v}$ for each point in the hydrograph. The outflow condition is specified in one or more downstream grid elements. The model requires the specification of the terrain surface as a uniformly spaced grid. Within the terrain surface grid, a computational grid, i.e. a domain for the calculations, must be specified. The Manning $n$ value should be assigned to each grid element to account for the hydraulic roughness of the terrain surface. The values can be spatially variable to account for differences in surface coverage (FLO-2D, 2009).

\subsection{Rainfall modelling}

The hourly measured rainfall data during the period of the 11 to 13 July 2008 was modelled as accumulated rainfall distributed all over the area domain in a real time (hourly time steps). Outflow sections were selected where the run-off rain of the modelled area domain is discharged. The outflow sections are artificial sections whose purpose is to discharge flow off the area domain system. For the Selvetta event, two zones were selected as outflow sections: (1) the scarp, where the release area is located and the slope failure occurred; and (2) the debris flow path channel, where the amount of rain can be an influencing factor in the mobility and the sediment concentration of the flow. Due to the Eulerian nature of the FLO-2D software and finite differences scheme, the parameter that mainly controls the numerical performance is the grid spacing. In the simulations using FLO-2D, the grid spacing was taken as $2 \mathrm{~m}$, which corresponds to the grid size in the digital elevation model. The result of the rainfallrunoff modelling is a water discharge hydrograph that is later added to the release volume of the failed mass in order to obtain a time stage debris flow release hydrograph (Fig. 5). 


\subsection{Debris flow modelling}

The estimation of the peak discharge inside the discharge hydrograph is of vital importance as it determines the maximum velocity and flow depth, momentum, impact forces, ability to overrun channel walls, as well as the run-out distance (Rickenmann, 1999; Whipple, 1992; Chen et al., 2007). For the estimation of the final debris flow hydrograph, the volumes of the entrained material estimated from measurements during the field work were introduced as an additional and variable sediment concentration into the hydrographs used in the FLO-2D model with the empirical formula use proposed by Mizuyama et al. (1992), who proposed a relation between the magnitude of the debris flow (volume in $\mathrm{m}^{3}$ ) and the peak discharge for muddy-debris flow (Eq. 5):

$$
Q_{\mathrm{p}}=0.0188 M^{0.790}
$$

where, $Q_{\mathrm{p}}$ is the peak discharge (in $\mathrm{m}^{3} \mathrm{~s}^{-1}$ ) and $M$ is the debris flow volume magnitude (in $\mathrm{m}^{3}$ ). A time-stage of sediment concentration was produced based on the shape of the hydrograph (Fig. 5). This was done to agree with observations that the peaks in debris flow hydrographs correspond to high sediment concentrations, while the final part of the hydrograph have a more diluted composition. The procedure also reproduced the distribution of sediment concentration influenced by a dilution in the falling tail of the hydrograph. The maximum and minimum concentrations were 0.55 and 0.25 , respectively.

Parameterization of the FLO-2D model was done by calibration, since no independent estimates of the model friction parameters were available. The calibration of the model was based on a trial-and-error selection of rheological models and parameters, and the adjustment of the input parameters which define the flow resistance. Parameters were adjusted until good agreement between the simulated and observed characteristics were accomplished with the following criteria: (i) velocity and height of the debris flow along the channel, (ii) final run-out, and (iii) accumulation pattern in the deposition area. The parameters that reasonably filled the calibration criteria and had the best results were $\tau_{y}=950 \mathrm{~Pa}$ and $\eta=1500 \mathrm{~Pa}$. These rheological parameters were calculated according to the sediment concentration of the flow (taken into account inside the debris flow hydrograph) and the constant values of $\alpha=0.0345$ for $\tau_{y}$ and 0.00283 for $\eta$; and $\beta=20.1$ for $\tau_{y}$ and 23.0 for $\eta$ were selected from O'Brien and Julien (1988). The chosen Manning n-values that characterize the roughness of the terrain were $=0.04 \mathrm{~s} \mathrm{~m}^{-1 / 3}$ where the flow was channelled, and $0.15 \mathrm{~s} \mathrm{~m}^{-1 / 3}$ in the deposition zone. The Manning $\mathrm{n}$-values and the constant value along the channel of $K=24$ were selected as suggested in the FLO-2D manual.

Figure 6 shows the maximum run-out and deposition modelled by FLO-2D and the field-measured extent of the event which underlines the good agreement of the simulation with

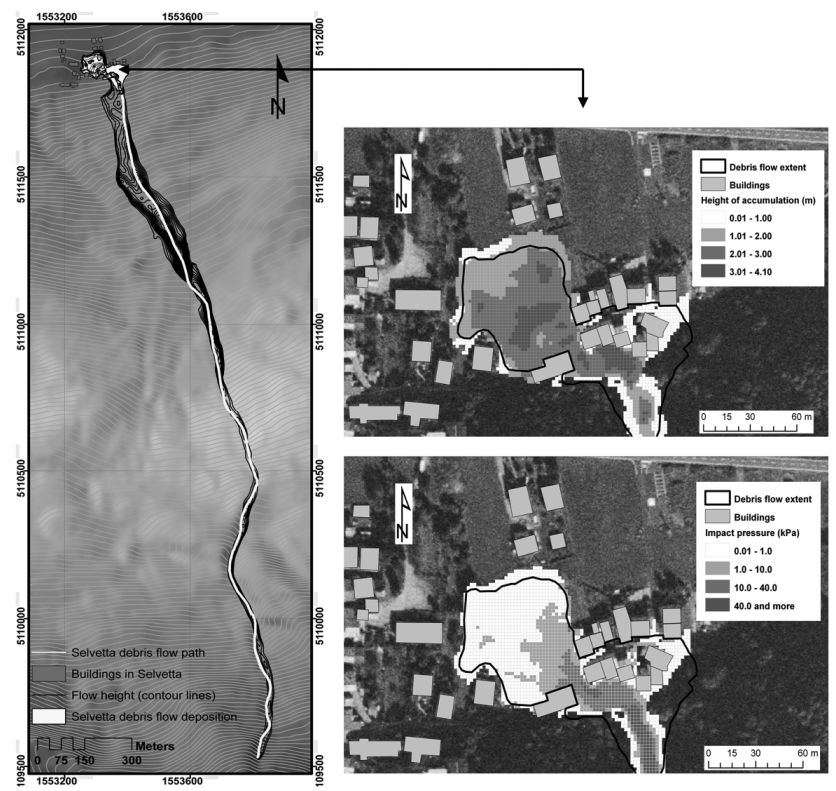

Fig. 6. Modelling results of the Selvetta debris flow (left). Comparison of the real and modelled debris flow run-out extent: The maximum heights of the accumulation and maximum impact pressures modelled by the FLO-2D model are shown (right).

what actually happened. The modelled heights of accumulation show good agreement with the real situation measured in the field. The highest accumulations are reached upslope from the destroyed and heavily damaged buildings, decreasing to the edges of the deposition area. It should be noted that in some cases the flow did not reach some of the lightly damaged structures. This is caused by the fact that FLO-2D does not model the destruction of the building and thus it remains as an obstacle causing the "shadow" effect. Apparent increase of heights of accumulation in the distal parts of the flow is most probably caused by imprecision in the used DEM. Highest values of impact pressure are reached immediately near the start of the apex. Afterwards, the pressures continuously decrease. This is caused by the progressive decrease of accumulation heights and velocities on the alluvial fan.

\section{Generation of vulnerability curves}

The Selvetta debris flow event represents an important case study due to the fact that both hazard information and damage information is available for a further analysis. The different range of damage to the buildings makes it possible to assess the vulnerability using a vulnerability function that relates the hazard intensity with the degree of damage. 


\subsection{Methodology}

In our approach, the vulnerability functions were calculated using damage data obtained from the official documents of damage assessment coupled with the information from the modelling outputs. This approach allows calculation of vulnerability functions using the height of debris accumulation and also the impact pressure. The impact pressure information is widely used in snow avalanche risk assessment but it is not widely applied for debris flows risk calculations.

The damage data was analyzed from the RASDA documents (RAccolta Scheda DAnni - Damage Assessment Form), which are mandatory to be drafted within $48 \mathrm{~h}$ after a disaster for claiming recompensation funding. For the Selvetta debris flow, these documents were prepared by the engineers of the General Directorate of Civil Protection of the Lombardy Region and the local police, where they estimated the losses in monetary values of each building. For each building, the approximate reconstruction value was calculated according to building type and size, using the data given in the Housing Prices Index prepared by the Engineers and Architects of Milan (DEI, 2006). All of the buildings were single to three storey brick masonry and concrete structures. The calculated reconstruction values of the buildings in the studied area ranged from $€ 66000$ to $€ 455000$; while the recorded damage ranged from about $€ 2000$ to $€ 290000$ (Table 1).

Vulnerability is defined by the fraction between the loss and the individual reconstruction value, and was calculated for each of the thirteen building structures that were affected by the debris flow event (Fig. 7). The obtained results were consequently coupled with the modelling results (height of accumulation, impact pressures). This allows developing vulnerability curves that relate the building vulnerability values with the process intensity. The generated physical vulnerability curves can be used as an approach for the estimation of the structural resistance of buildings affected by a debris flow event.

\subsection{Vulnerability curve using heights of accumulation}

Height of accumulation values were extracted for each affected building. For every building the maximum and minimum heights of accumulation varied a lot. As a consequence, an average height near building walls oriented towards the flow direction was considered. Figure 8 shows the relationship between the vulnerability and deposition height values.

Figure 8 indicates that the vulnerability increases with increasing deposition height. We propose to use a logistic function (Eq. 6). The calculated function has coefficient of determination $\left(r^{2}\right)$ is 0.99 , for intensities between 0 and $3.63 \mathrm{~m}$ :

$$
\begin{array}{ll}
v=\frac{1.49 \times|h / 2.513|^{|-1.938|}}{1+|h / 2.513|^{-1.938 \mid}} & \text { for } h \leq 3.63 \mathrm{~m} \\
v=1 & \text { for } h>3.63 \mathrm{~m}
\end{array}
$$

where, $V$ is vulnerability and $h$ is the modelled height of accumulation. From its definition the vulnerability cannot exceed 1, thus for intensities higher than $3.63 \mathrm{~m}$, the vulnerability is equal to 1 .

\subsection{Vulnerability curve using impact pressures}

Impact pressure values were extracted in the same way as accumulation heights considering the values near building walls oriented towards the flow direction. Maximum modelled impact pressures were used to calculate the vulnerability function (Fig. 9).

A logistic function (Eq. 7) which fits the results has a high coefficient of determination $\left(r^{2}\right)$ reaching 0.98 for impact pressures up to $37.49 \mathrm{kPa}$ :

$$
\begin{array}{ll}
v=\frac{1.596 \times|P / 28.16|^{|-1.808|}}{1+|P / 28.16|^{-1.808 \mid}} & \text { for } P \leq 37.49 \mathrm{kPa} \\
v=1 & \text { for } P>37.49 \mathrm{kPa}
\end{array}
$$

where, $V$ is vulnerability and $P$ is the modelled impact pressure. As vulnerability cannot exceed 1 , for intensities higher than $37.49 \mathrm{kPa}$, the vulnerability is equal to 1 .

\subsection{Vulnerability curve using kinematic viscosity}

Using the same approach as described previously, a vulnerability function where the momentum of the flow is taken into account is proposed. This function relates the maximum velocity of the flow and its height at the moment of impact with a structure (Fig. 10).

A logistic function which fits the results has a high coefficient of determination $\left(r^{2}\right)$ reaching 0.98 for kinematic viscosity up to $5.32 \mathrm{~m}^{2} \mathrm{~s}^{-1}$ (Eq. 8):

$$
\begin{array}{ll}
v=\frac{5.38 \times|\mathrm{kv} / 29.26|^{|-0.867|}}{1+|\mathrm{kv} / 29.26|^{|-0.867|}} & \text { for } P \leq 5.32 \mathrm{~m}^{2} \mathrm{~s}^{-1} \\
v=1 & \text { for } P>5.32 \mathrm{~m}^{2} \mathrm{~s}^{-1}
\end{array}
$$

where, $V$ is vulnerability and $\mathrm{kv}$ is the modelled kinematic viscosity. As vulnerability cannot exceed 1 , for intensities higher than $5.32 \mathrm{~m}^{2} \mathrm{~s}^{-1}$, the vulnerability is equal to 1 .

\section{Discussion and conclusions}

Three physical vulnerability curves that relate the intensity of debris flows and the economic losses were derived from the Selvetta debris flow event. The event was reconstructed in a geomorphologic, empirical, and numerical approach using a quadratic rheological model. Field geomorphologic investigations were directed towards evidences related to the behaviour of the flow and different sections of the flow path were identified regarding the activity and deposits of the flow during its course. The FLO-2D model is applied for the backcalculation and the results coincide in a good manner with the real event. The most significant results obtained by the model are the maximum height, maximum velocities, and 
Table 1. Values used for the vulnerability functions assessment.

\begin{tabular}{|c|c|c|c|c|c|c|c|c|c|c|}
\hline $\begin{array}{l}\text { Building } \\
\text { No. }\end{array}$ & $\begin{array}{l}\text { Building } \\
\text { type }\end{array}$ & $\begin{array}{l}\text { No. of } \\
\text { floors }\end{array}$ & $\begin{array}{l}\text { Building } \\
\text { use }\end{array}$ & $\begin{array}{c}\text { House price } \\
\text { index } \\
\left(\text { EUR m }^{-2}\right)\end{array}$ & $\begin{array}{r}\text { Building } \\
\text { value }\end{array}$ & $\begin{array}{l}\text { Reported } \\
\text { damage }\end{array}$ & Vulnerability & $\begin{array}{c}\text { Model flow } \\
\text { height } \\
\text { " } H "(\mathrm{~m})\end{array}$ & $\begin{array}{l}\text { Model Max } \\
\text { velocity } \\
\text { " } V "\left(\mathrm{~m} \mathrm{~s}^{-1}\right)\end{array}$ & $\begin{array}{c}\text { Model impact } \\
\text { pressure } \\
\text { " } P "(\mathrm{kPa})\end{array}$ \\
\hline 1 & brick masonry & 3 & generic use & $€ 881$ & $€ 426900$ & $€ 284251$ & 0.666 & 2.29 & 1.37 & 22.03 \\
\hline 2 & brick masonry & 2 & generic use & $€ 881$ & $€ 129720$ & $€ 3000$ & 0.023 & 0.68 & 0.29 & 1.66 \\
\hline 3 & brick masonry & 3 & generic use & $€ 881$ & $€ 256190$ & $€ 256190$ & 1.000 & 3.54 & 1.48 & 35.86 \\
\hline 4 & brick masonry & 2 & generic use & $€ 881$ & $€ 66240$ & $€ 66240$ & 1.000 & 3.70 & 1.46 & 38.06 \\
\hline 5 & brick masonry & 2 & generic use & $€ 881$ & $€ 216200$ & $€ 120100$ & 0.556 & 2.00 & 1.25 & 23.89 \\
\hline 6 & brick masonry & 2 & generic use & $€ 881$ & $€ 146760$ & $€ 20000$ & 0.136 & 0.47 & 0.40 & 8.53 \\
\hline 7 & brick masonry & 2 & generic use & $€ 881$ & $€ 105720$ & $€ 2000$ & 0.019 & 0.15 & 0.26 & 0.03 \\
\hline 8 & brick masonry & 2 & generic use & $€ 881$ & $€ 108100$ & $€ 2100$ & 0.019 & 0.15 & 0.26 & 0.03 \\
\hline 9 & brick masonry & 2 & generic use & $€ 881$ & $€ 170760$ & $€ 3000$ & 0.018 & 0.40 & 0.29 & 0.04 \\
\hline 10 & brick masonry & 2 & generic use & $€ 881$ & $€ 129720$ & $€ 2000$ & 0.015 & 0.18 & 0.29 & 0.01 \\
\hline 12 & brick masonry & 2 & generic use & $€ 881$ & $€ 108100$ & $€ 2400$ & 0.022 & 0.28 & 0.25 & 3.26 \\
\hline 13 & brick masonry & 3 & generic use & $€ 881$ & $€ 455360$ & $€ 290167$ & 0.637 & 2.10 & 1.33 & 20.21 \\
\hline 30 & brick masonry & 2 & generic use & $€ 881$ & $€ 170760$ & $€ 60000$ & 0.351 & 1.26 & 0.94 & 13.61 \\
\hline
\end{tabular}
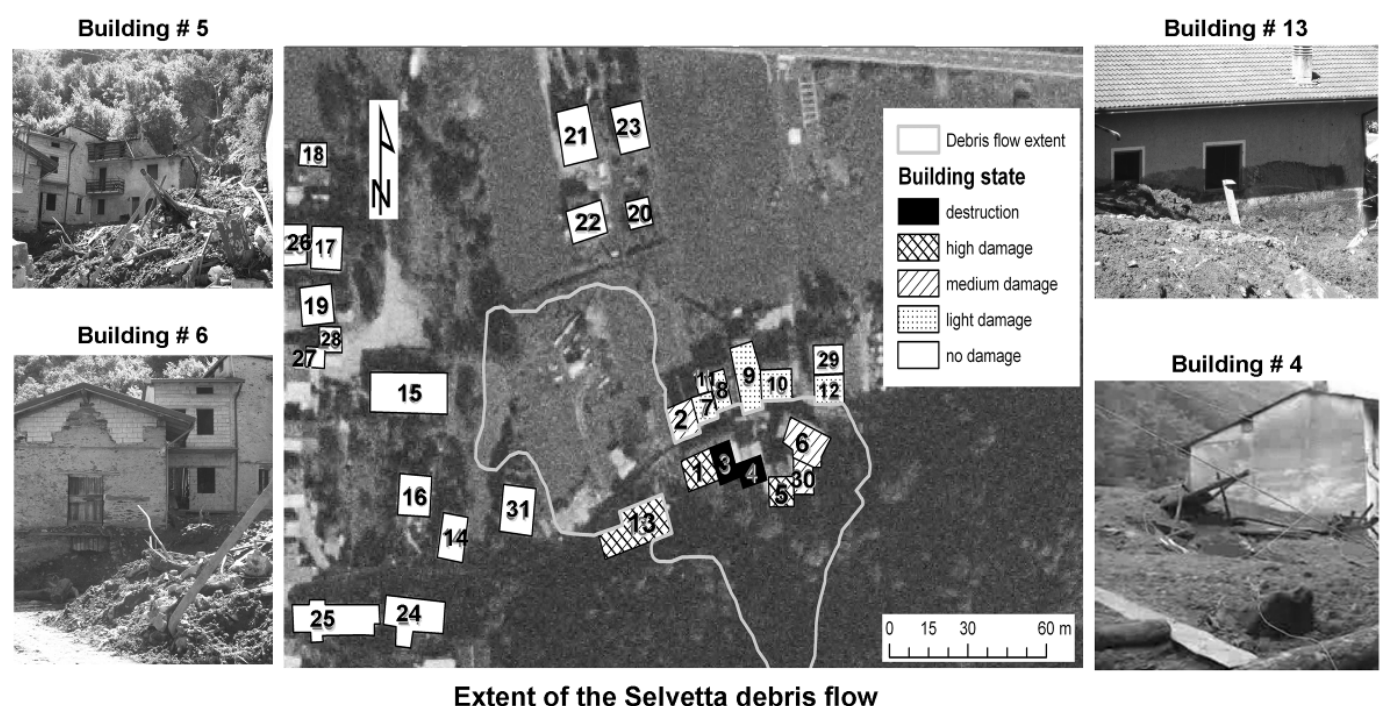

Extent of the Selvetta debris flow

Fig. 7. Extent of the Selvetta debris flow damage to buildings is shown. Destruction: $V=1$; heavy damage: $V=0.5-1$; medium damage: $V=0.1-0.5$; light damage: $V=0-0.1$.

impact pressures reached by the flow in each cell throughout the entire simulation. These outputs were investigated in terms of the resulting damage to the affected buildings. The intensity parameters used for the generation of the vulnerability curves are based on the height of accumulation, maximum velocity, and impact pressures. However, more data is needed to increase the robustness of the curves.

The flow height vulnerability function obtained in this study suggests different vulnerabilities compared to those obtained using the equations given by Fuchs et al. (2007) and Akbas et al. (2009) (Fig. 11). Vulnerability 1.0 (total destruction) is reached at $3.63 \mathrm{~m}$, which is considerably higher than $2.5 \mathrm{~m}$ of Akbas et al. (2009) and 3.0 m of Fuchs et al. (2007). However, the number of data points in both studies is limited; therefore, it is not possible to reach a robust conclusion about whether the observed discrepancy is the result of the difference in modelling, construction techniques, or a combination of both. The difference may also be partly due to the estimation of the average accumulation height.

The calculated impact pressure vulnerability function was compared to two functions used in snow avalanche risk assessment (Fig. 12). Similar behaviour of the function can be noticed in comparison with the linear function of Barbolini et al. (2004) which was developed from avalanche data for West Tyrol, Austria. Wilhelm (1998) proposed two different relationships for vulnerabilities higher than 0.5: the former (i) continues its linear trend and reaches vulnerability 1.0 at $34 \mathrm{kPa}$; the latter (ii) indicates that structures are considered beyond repair in cases of impact pressures higher than $25 \mathrm{kPa}$. These functions of Wilhelm (1998) were calculated 


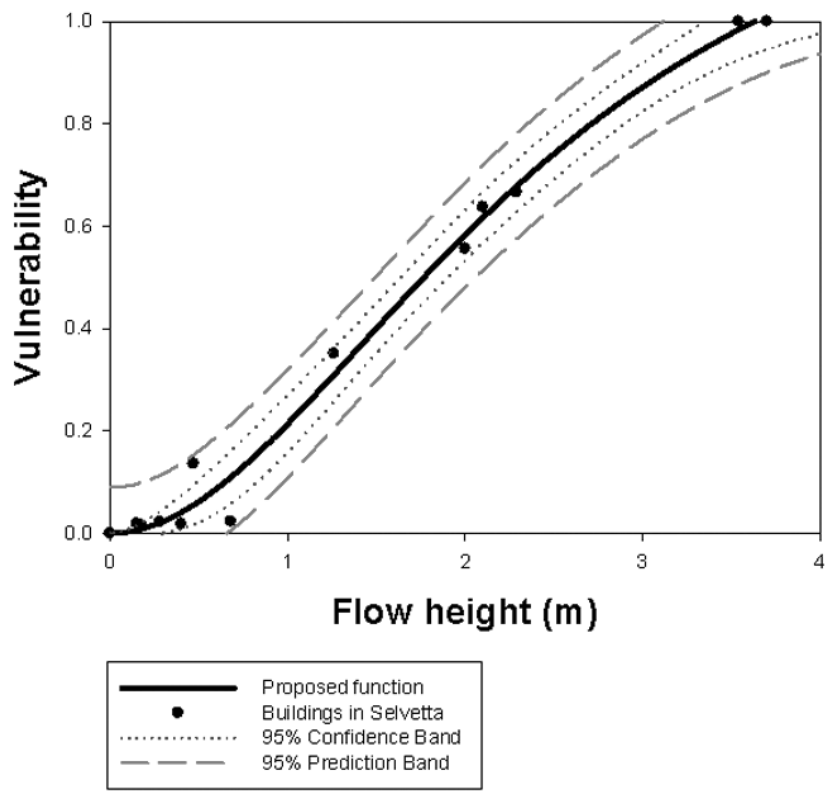

Fig. 8. Proposed vulnerability function for accumulation heights obtained from the modelling.

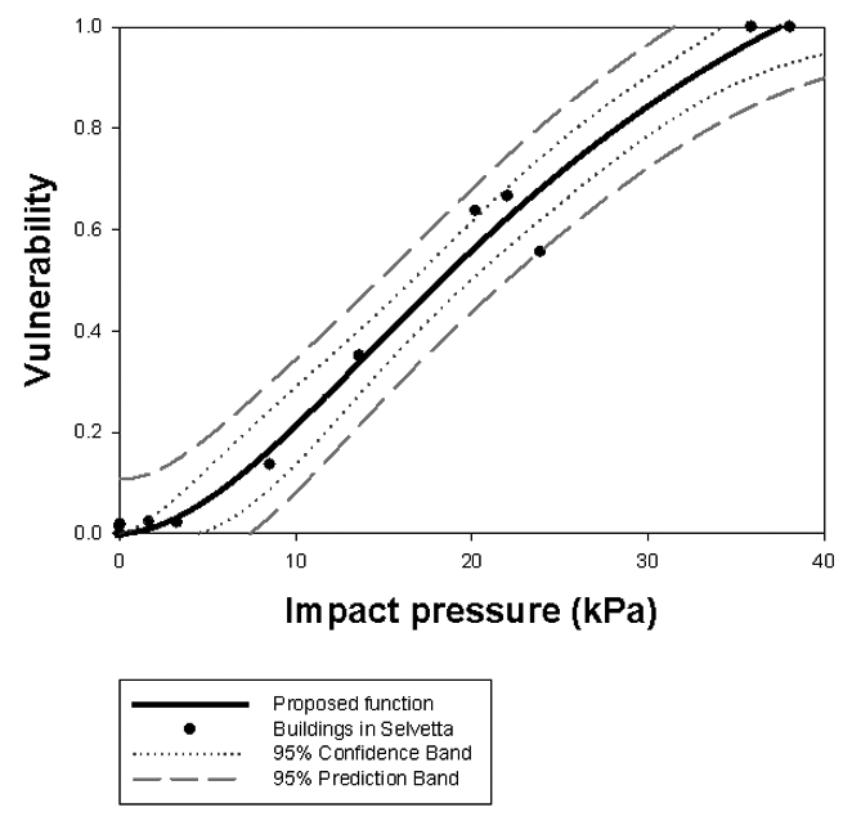

Fig. 9. Proposed vulnerability function for modelled impact pressures.

from data about reinforced structures impacted by avalanches in Switzerland. Compared to our equation, results using the Wilhelm (1998) functions vary a lot in lower vulnerabilities (up to 0.6). At vulnerability of $0.9(33 \mathrm{kPa})$, our function converges with the function of Wilhelm (a) and reaches $V=1.0$ at $37.49 \mathrm{kPa}$. This is also different from Barbolini et al. (2004), who put vulnerability of 1.0 at impact pressure of $34 \mathrm{kPa}$ (similar as Wilhelm, 1998).

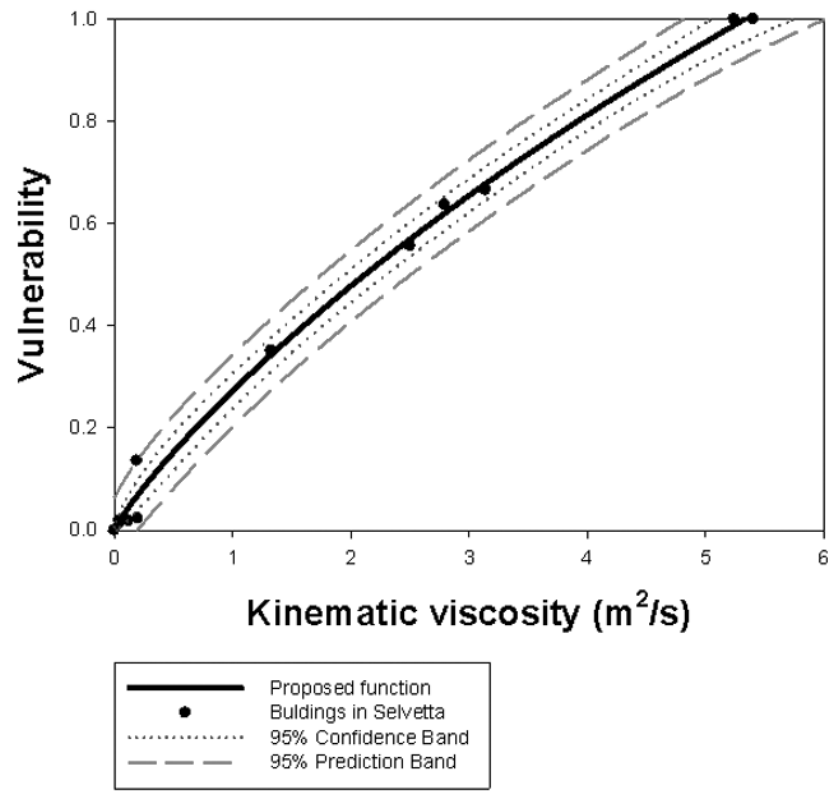

Fig. 10. Proposed vulnerability function for accumulation heights obtained from the modelling.

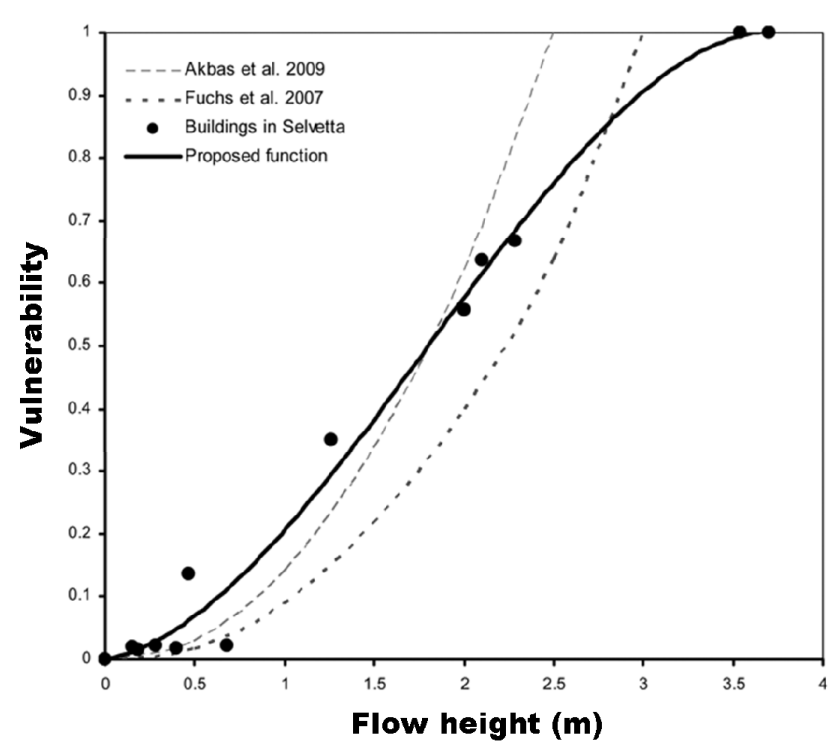

Fig. 11. Comparison of the proposed vulnerability functions proposed by Akbas et al. (2009), Fuchs et al. (2007) and the vulnerability curve calculated from the Selvetta debris flow event in 2008.

The use of numerical modelling for the simulation of the dynamics of debris flows in the generation of vulnerability curves can present an advantage in terms that the intensity outputs (e.g. flow height and pressures) are straight forward and can be spatially displayed. The results can be overlaid with the elements at risk and detailed physical information can be obtained in a specific area. The approach presented here can be assumed as an approximation of a building 


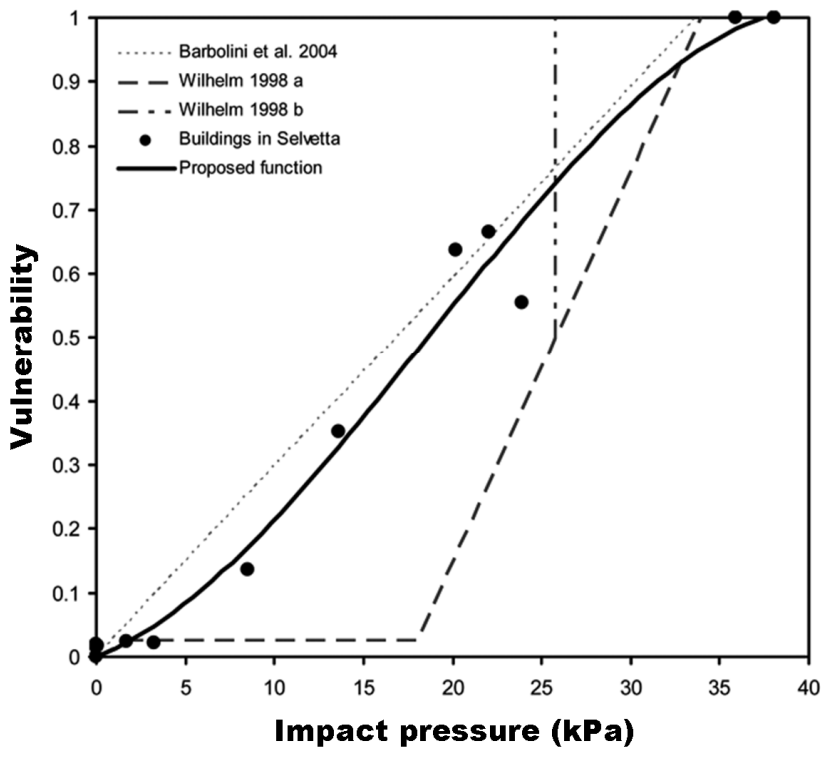

Fig. 12. Comparison of the proposed vulnerability functions proposed by Barbollini et al. (2004), Wilhelm (1998), and the vulnerability curve calculated from the Selvetta debris flow event 2008.

resistance to endure a debris flow, which is information that is difficult to obtain directly on the field. Another important advantage in the employment of run-out models is that the intensity factors of the hazard can be analyzed in conjunction with the physical vulnerability of the elements at risk, making it easier to quantify the suffered consequences. The aim to present different types of vulnerability curves in this analysis is to help the decision makers decide which type of intensity description best fits their needs and affected area. It can be argued that impact pressure vulnerability function can be used to measure the structure resistance itself, whereas using a flow height vulnerability function can also take into account the contents inside the structure.

The presented vulnerability functions do not conflict with the damage state probabilities functions that plot probabilities of the different damage states of a structure (e.g. slight damage, moderate damage, complete collapse). Whereas in the damage stage functions the proposed stages ranges are determined qualitatively in a subjective manner and the probability of complete collapse can be smaller than 1 , in the proposed vulnerability curves the degree of damage is determined directly by the intensity of the event and a complete collapse takes a value of 1 . For this reason, the values determined by the vulnerability functions can be used directly in a quantitative risk assessment.

However, shortcomings in our analysis still exist and further research needs to be done regarding them. One of the major shortcomings is the insufficient data points regarding the affected elements at risk and the variation in values due to the differences in building quality, state, and structural characteristics. This should also be complimented by collecting more data of damaged buildings affected by debris flows, organizing them according to the type and use. This kind of description plays a very important role for the analysis, as in the case where damage to buildings contents will be higher than to the building structure itself (i.e. shops and warehouses). Hence, a better estimation of the reported damage should be assessed based on structural and non-structural damage. A complete database with detailed information about building type, building use, building characteristics, building quality and state, and the amount of recorded damage (physical and economic), should lead to a better estimation of debris flow vulnerability curves.

There is also a high degree of uncertainty regarding the use of the model to simulate the different processes that played a key role in the evolution of the Selvetta debris flow event. Assumptions and empirical laws were used based on the need of inputs that FLO-2D model requires and the behaviour of the process (e.g. addition of sediment in the discharge hydrograph to model the entrained material and peak discharge). Uncertainty regarding each modelled process has to be quantified in the future to reduce uncertainty. Although dynamic debris flow run-out models has been used with regularity in the past to reconstruct past events by calibration of the input parameters, there are still some limitations in the physical description of the parameters defining the applied rheology (quadratic).

Nevertheless, the presented approach attempts to propose a quantitative method to estimate the vulnerability of an exposed element to a debris flow that can be independent on the temporal occurrence of the hazard event.

Acknowledgements. This work has been supported by the Marie Curie Research and Training Network "Mountain Risks" funded by the European Commission (2007-2010, Contract MCRTN-35098). The authors would like to thank the reviewers for their comments, which improved the quality of the paper

Edited by: P. Reichenbach

Reviewed by: B. Pradhan and P. Gehl

\section{References}

Aleotti, P., Ceriani, M., Fossati, D., Polloni, G., and Pozza, F.: I fenomeni franosi connesi alle precipitazioni del Novembre 2002 in Valtellina (Soil slips and debris flows triggered by the november 2002 storms in Valtellina, Italian Central Alps), International Symposium Interpraevent 2004, Riva/Trient, Italy, 11-20, 2004.

Barbolini, M., Cappabianca, F., and Sailer, R.: Empirical estimate of vulnerability relations for use in snow avalanche risk assessment, in: Risk analysis IV, edited by: Brebbia, C., WIT Press, Southampton, 533-542, 2004.

Beguería, S., van Asch, Th. W. J., Malet, J.-P., and Gröndahl, S.: A GIS-based numerical model for simulating the kinematics of mud and debris flows over complex terrain, Nat. Hazards Earth Syst. Sci., 9, 1897-1909, doi:10.5194/nhess-9-1897-2009, 2009. 
Bell, R. and Glade, T.: Quantitative risk analysis for landslides - Examples from Bíldudalur, NW-Iceland, Nat. Hazards Earth Syst. Sci., 4, 117-131, doi:10.5194/nhess-4-117-2004, 2004.

Bertrand, D., Naaim, M., and Brun, M.: Physical vulnerability of reinforced concrete buildings impacted by snow avalanches, Nat. Hazards Earth Syst. Sci., 10, 1531-1545, doi:10.5194/nhess-101531-2010, 2010.

Calvo, B. and Savi, F.: A real-world application of Monte Carlo procedure for debris flow risk assessment, Comput. Geosci., 35(5), 967-977, 2008.

Cancelli, A. and Nova, R.: Landslides in soil debris cover triggered by rainstorms in Valtellina (Central Alps - Italy), in: Proceedings of 4th International Conference and Field Workshop on Landslides, The Japan Geological Society, Tokyo, 267-272, 1985.

Cappabianca, F., Barbolini, M., and Natale, L.: Snow avalanche risk assessment and mapping: A new method based on a combination of statistical analysis, avalanche dynamics simulation and empirically-based vulnerability relations integrated in a GIS platform, Cold Reg. Sci. Technol., 54(3), 193-205, 2008.

Castellanos Abella, E. A.: Local landslide risk assessment, in: Multi-scale landslide risk assessment in Cuba, edited by: Castellanos Abella, E.A., Utrecht, Utrecht University, ITC Dissertation, 154, 193-226, 2008.

Chen, H. and Lee, C. F.: Numerical simulation of debris flows, Can. Geotech. J., 37, 146-160, 2000

Chen, H., Crosta, G. B., and Lee, C. F.: Erosional effects on runout of fast landslides, debris flows and avalanches: A numerical investigation, Geotechnique, 56(5), 305-322, 2006.

Chen, N. S., Yue, Z. Q., Cui, P., and Li, Z. L.: A rational method for estimating maximum discharge of a landslide-induced debris flow: A case study from southwestern China, Geomorphology, 84(1-2), 44-58, 2007.

Crosta, G., Marchetti, M., Guzzetti, F., and Reichenbach, P.: Morphological classification of debris-flow processes in SouthCentral Alps (Italy), Proceedings of the 6th International IAEG Congress, Amsterdam, 1565-1572, 1990.

Crosta, G. B., Dal Negro, P., and Frattini, P.: Soil slips and debris flows on terraced slopes, Nat. Hazards Earth Syst. Sci., 3, 31-42, doi:10.5194/nhess-3-31-2003, 2003.

Crosta, G. B., Fratinni, P., Fugazza, F., Caluzzi, L., and Chen, J.: Cost-benefit analysis for debris avalanche risk management, in: Landslide Risk Management, edited by: Hungr, O., Fell, R., Couture, R., and Eberhardt, E., Taylor \& Francis, London, 533541, 2005.

DEI: Prezzi Tipologie Edilizie 2006, DEI Tipografia del Genio Civilie, CD-ROM, 2006.

Douglas, J.: Physical vulnerability modelling in natural hazard risk assessment, Nat. Hazards Earth Syst. Sci., 7, 283-288, doi:10.5194/nhess-7-283-2007, 2007.

Duzgun, H. S. B. and Lacasse, S.: Vulnerability and acceptable risk in integrated risk assessment framework, in: Landslide risk management, edited by: Hungr, O., Fell, R., Couture, R., and Eberhardt, E., Balkema, Rotterdam, 505-515, 2005.

Fell, R. and Hartford, D.: Landslide risk management, in: Landslide risk assessment, edited by: Cruden, D. and Fell, R., Balkema, Rotterdam, 51-109, 1997.

Fell, R., Ho, K. K. S., Lacasse, S., and Leroi, E.: A framework for landslide risk assessment and management, in: Landslide Risk Management, edited by: Hungr, O., Fell, R., Couture, R., and
Eberhardt, E., Taylor \& Francis, London, 533-541, 2005.

FLO-2D: Reference manual, 2009, available at: http://www.flo-2d. com/wp-content/uploads/FLO-2D-Reference-Manual-2009. pdf, last access: 2010.

Fuchs, S., Heiss, K., and Hübl, J.: Towards an empirical vulnerability function for use in debris flow risk assessment, Nat. Hazards Earth Syst. Sci., 7, 495-506, doi:10.5194/nhess-7-4952007, 2007.

Galli, M. and Guzzetti, F.: Landslide Vulnerability Criteria: A Case Study from Umbria, Central Italy, Environ. Manage., 40(4), 649665, 2007.

Gamma, P.: DF-Walk: Ein Murgang-Simulationsprogramm zur Gefahrenzonierung (Geographica Bernensia, G66), University of Bern, 2000 (in German).

Glade, T.: Vulnerability assessment in landslide risk analysis, Die Erde, 134, 123-146, 2003.

Haugen, E. D. and Kaynia, A. M.: Vulnerability of structures impacted by debris flow, in: Landslides and Engineered Slopes, edited by: Chen, Z., Zhang, J.-M., Ho, K., Wu, F.-Q., and Li, Z.-K., Taylor \& Francis, London, 381-387, 2008.

HAZUS-MH: HAZUS - FEMAs Methodology for Estimating Potential Losses from Disasters, available at: http://www.fema.gov/ plan/prevent/hazus/index.shtm, 2010.

Heinimann, H. R.: Risikoanalyse bei gravitativen Naturgefahren, Umwelt-Materialien, 107/1, 115 pp., 1999.

Hungr, O.: A model for the runout analysis of rapid flow slides, debris flows and avalanches, Can. Geotech. J., 32, 610-623, 1995.

Jakob, M. and Weatherly, H.: Debris flow hazard and risk assessment, Jones Creek, Washington, in: Landslide Risk Management, edited by: Hungr, O., Fell, R., Couture, R., and Eberhardt, E., Taylor \& Francis, London, 533-541, 2005.

Kaynia, A. M., Papathoma-Köhle, M., Neuhäuser, B., Ratzinger, K., Wenzel, H., and Medina-Cetina, Z.: Probabilistic assessment of vulnerability to landslide: Application to the village of Lichtenstein, Baden-Württemberg, Germany, Eng. Geol., 101(1-2), 33-48, 2008.

Kwan, J. S. H. and Sun, H. W.: An improved landslide mobility model, Can. Geotech. J., 43, 531-539, 2006.

Leone, F., Asté, J. P., and Leroi, E.: Vulnerability assessment of elements exposed to massmovements: working toward a better risk perception, in: Landslides- Glissements de Terrain, edited by: Senneset, K., Balkema, Rotterdam, 263-270, 1996.

Li, Z., Nadim, F., Huang, H., Uzielli, M., and Lacasse, S.: Quantitative vulnerability estimation for scenario-based landslide hazards, Landslides, 7(2), 125-134, 2010.

Liu, X. and Lei, J.: A method for assessing regional debris flow risk: an application in Zhaotong of Yunnan province (SW China), Geomorphology, 52(3-4),181-191, 2003.

Luino, F.: Sequence of instability processes triggered by heavy rainfall in the northern Italy, Geomorphology, 66(1-4), 13-39, 2005.

Mavrouli, O. and Corominas, J.: Vulnerability of simple reinforced concrete buildings to damage by rockfalls, Landslides, 7(2), 169-180, 2010.

McClung, D. M.: Superelevation of flowing avalanches around curved channel bends, J. Geophys. Res., 106(B8), 16489-16498, 2001.

Mizuyama, T., Kobashi, S., and Ou, G.: Prediction of debris flow peak discharge, in: International Symposium Interpraevent, Bern, 99-108, 1992. 
Muir, I., Ho, K. S. S., Sun, H. W., Hui, T. H. H., and Koo, Y. C.: Quantitative risk assessment as applied to natural terrain landslide hazard management in a mid-levels catchment, Hong Kong, in: "Geohazards", edited by: Nadim, F., Pöttler, R., Einstein, H., Klapperich, H., and Kramer, S., ECI Symposium Series, P07, 8 pp., 2006.

Nadim, F. and Kjekstad, O.: Assessment of global high-risk landslide disaster hotspots, in: Disaster Risk Reduction, edited by: Sassa, K. and Canuti, P., Springer-Verlag, Berlin, 213-222, 2009.

O'Brien, J. S. and Julien, P. Y.: Laboratory analysis of mudflow properties, J. Hydraul. Eng., 114(8), 877-887, 1988.

O'Brien, J. S., Julien, P. Y., and Fullerton, W. T.: Two-dimensional water flood and mudflow simulation, J. Hydraul. Eng., 119(2), 244-261, 1993.

Pascale, S., Sdao, F., and Sole, A.: A model for assessing the systemic vulnerability in landslide prone areas, Nat. Hazards Earth Syst. Sci., 10, 1575-1590, doi:10.5194/nhess-10-15752010, 2010.

Prochaska, A., Santi, P., Higgins, J., and Cannon, S.: A study of methods to estimate debris flow velocity, Landslides, 5(4), 431444, 2008.

Remondo, J., Bonachea, J., and Cendrero, A.: Quantitative landslide risk assessment and mapping on the basis of recent occurrences, Geomorphology, 94(3-4), 496-507, 2008.

Rickenmann, D.: Debris Flows 1987 in Switzerland: Modelling and Sediment Transport (IAHS Publication No. 194, 371-378), International Association of Hydrological Sciences, Chrirstchurch, New Zealand, 1990.
Rickenmann, D.: Empirical Relationships for Debris Flows, Nat. Hazards, 19(1), 47-77, 1999.

Uzielli, M., Nadim, F., Lacasse, S., and Kaynia, A. M.: A conceptual framework for quantitative estimation of physical vulnerability to landslides, Eng. Geol., 102(3-4), 251-256, 2008.

van Asch, T. W. J., Malet, J.-P., van Beek, L. P. H., and Amitrano, D.: Techniques, issues and advances in numerical modelling of landslide hazard, B. Soc. Géol. Fr., 178(2), 65-88, 2007.

van Westen, C. J., van Asch, T. W. J., and Soeters, R.: Landslide hazard and risk zonation - why is it still so difficult?, B. Eng. Geol. Environ., 65, 167-184, 2006.

Whipple, K. X.: Predicting debris-flow runout and deposition on fans: the importance of the flow hydrograph, in: Erosion, DebrisFlows and Environment in Mountain Regions: Proceedings of the Chengdu Symposium, edited by: Walling, D., Davies, T., and Hasholt, B., International Association of Hydrological Sciences, 209, 337-345, 1992.

Wilhelm, C.: Quantitative risk analysis for evaluation of avalanche protection projects, in: Proceedings of the 25 Years of Snow Avalanche Research, Oslo, Norway, 288-293, 1998.

Zêzere, J. L., Garcia, R. A. C., Oliveira, S. C., and Reis, E.: Probabilistic landslide risk analysis considering direct costs in the area north of Lisbon (Portugal), Geomorphology, 94(3-4), 467-495, 2008.

Zimmerman, M. N.: Analysis and management of derbis-flow risks at Sörenberg, Switzerland, in: Debris-Flow Hazards and Related Phenomena, edited by: Jakob, M. and Hungr, O., Praxis, Springer, Berlin, Heidelberg, 305-324, 2005. 